\title{
THE FIRST HALF-CENTURY OF ORTHOPAEDIC SURGERY IN NEW ZEALAND
}

\author{
Coates Milsom, Alckland, New Zealand
}

It is perhaps not surprising that in this country, with a population of less than two millions, enjoying such ample living space and with diet so abundant, the incidence of orthopaedic disorders is low. This is one of the reasons why original clinical contributions from New Zealand have been limited, and why many of our surgeons have sought postgraduate training overseas. Nowhere are the ties of Empire more strong, and such training has usually been gained in England. Not a few of our surgeons have stayed there and, although it is a loss to their home country, we still take pride in their achievement: Sir Harold Gillies, whose pioneer work in plastic surgery has gained world renown; Sir Archibald McIndoe and Rainsford Mowlem, who enhanced that reputation; and many others to whom reference is made in this article.

Even before orthopaedic surgery was known in this country an important contribution was made by Sir Frederic Truby King who applied scientific principles to the feeding and welfare of children and their mothers. He founded the Royal New Zealand Society for the Health of Women and Children, organised mothercraft centres in many parts of the world and even in such distant parts as London itself, and was directly responsible for preventing many of the disorders that would otherwise have necessitated orthopaedic treatment.

The First World War-Before the first World War, orthopaedics was not recognised as a special branch of surgery, but the opportunity was then presented to many surgeons who trained under the great Sir Robert Jones. Courses were organised by him and by R. C. Elmslie at the Military Orthopaedic Hospital at Shepherd's Bush, Alder Hey Hospital in Liverpool, and the Orthopaedic Hospital at Baschurch where they made the acquaintance of Dame Agnes Hunt. Colonel D. S. Wylie was entrusted with development of the first New Zealand Military Orthopaedic Unit, and Renfrew White, Wallis, Mill, Ulrich and Gower who trained with him must be named as the first orthopaedic surgeons of New Zealand. Supplied with British equipment and accompanied by plaster technicians, ward sisters and a massage staff they returned in 1918 and forthwith established a unit at Christchurch.

Renfrew White was quickly appointed to the staff of the Dunedin Hospital as clinical teacher and lecturer in orthopaedic surgery, and he carried out these duties until his retirement in 1949. His influence upon successive generations of students, with the stimulus of his incisive teaching which made them think for themselves, has been one of the greatest contributions towards the development of orthopaedics. He will be remembered also for his masterly technique, his writings, and his insistence on the cultural education of students.

In 1920 two more hospitals were opened at Trentham and Rotorua for the treatment and rehabilitation of returned servicemen. At the King George V Hospital at Rotorua, W. S. Wallis was appointed superintendent and orthopaedic surgeon; from what was at first a purely military orthopaedic establishment he made an important centre of treatment of civilian orthopaedic cases and finally a general hospital for the district. The original military orthopaedic unit stood in the grounds of the Christchurch Public Hospital which later took it over and developed an orthopaedic department under the guidance of Leslie Will, who arrived back from a period of training in England a year or two later.

From these early beginnings we may pass to the " middle period " marked by the arrival of Alexander Gillies in Wellington in 1929. Like the original six, he had trained in England and had also spent some years in the United States of America. The influence of Hugh Owen Thomas and Robert Jones was thus reinforced. Gillies has been responsible for the guidance and development of the New Zealand Crippled Children's Society, and to him must be attributed the development of travelling clinics for the early detection of orthopaedic 
conditions in children. This period is also associated with the names of Walter Robertson in Wellington, and of Cuthbert McCaw and Keith Macky in Auckland.

Influence of the Second World War-Each of the three general hospitals of the New Zealand Division in the Middle East had on its staff one orthopaedic surgeon drawn from the ranks of assistant surgeons of the metropolitan hospitals. Each hospital cared for its own quota of major fractures and orthopaedic cases. Of the junior medical officers attached to the orthopaedic wards, many became interested in the pursuit of the specialty. In New Zealand itself, civilian hospitals were expanded and civilian orthopaedic surgeons undertook the care of the returned wounded besides their ordinary duties. With the outbreak of war in the Pacific area, the United States Forces established several large field-hospitals in the country, and New Zealand surgeons thus acquired a valued opportunity of comparing their practice with that of another nation. Clinical demonstrations and meetings gave a broader outlook, especially in the matter of equipment and appliances.

Now, in 1950, the position has been reached where the desire to emulate these pioneers has encouraged many graduates to seek orthopaedic training in Great Britain. Not only the main cities but many of the smaller towns now possess separate orthopaedic units. At Auckland, the largest city, there are on the Staff of the General Hospital three senior and three assistant orthopaedic surgeons, one full-time resident senior orthopaedic surgeon and a registrar. No less than seven former house surgeons of the hospital are now training as orthopaedic surgeons in England.

Physiotherapy, Rehabilitation and Resetllement-The scheme for rehabilitation of wounded servicemen has been highly successful. Severely handicapped men were first tested in departments of occupational therapy to discover their capabilities. Less handicapped patients were sent directly to training schools after examination by vocational guidance officers; they learned carpentry, bootmaking, artificial-limb making, bee keeping, poultry farming, french polishing and cabinet-making. Occupational therapy was instituted during the latter part of the war. A training school was developed, and occupational therapists are now available in most of the main hospitals and are doing especially useful work in the mental hospitals and with geriatric patients.

In the early days massage was practised by privately trained and sometimes untrained individuals, but in 1920 the Masseurs Registration Act was passed; later a school of physiotherapy was established in Dunedin from which graduates have travelled far from New Zealand. The recent Physiotherapy Act of 1949 has consolidated the position of these trained medical auxiliaries whose work is valued so highly.

The Crippled Children's Society-The Wellington Rotary Club, after an address by Alexander Gillies in 1930, investigated the Crippled Children's Movement in the United States of America which was started in 1913 by the Rotary Club of Syracuse. By 1935 the New Zealand Crippled Children's Society was formally established, and supported by contributions from local Rotary Clubs and the generosity of the Wilson family; Lord Nuffield later made a magnificent donation which formed the Nuffield Trust Fund. The Society in 1948 had nearly five thousand cases on its register and had become a national organisation. Working with the Department of Health it undertook the welfare, diagnosis, treatment and vocational training of crippled children. To facilitate the detection of untreated cases in country areas a system of travelling clinics had been created in 1932, inspired by the Shropshire clinics of the Robert Jones and Agnes Hunt Orthopaedic Hospital in England. These clinics are now country-wide. Though it was estimated in 1948 that there were still two thousand untreated cases, the clinics have already reaped a harvest and many thousands of crippled children-who otherwise would never have been seen-have been cured. Crutches, wheel chairs, special footwear and clothing have also been provided; and the Wilson family have maintained their generosity in giving their beautiful home and grounds in Takapuna as a Children's Orthopaedic Home. 
The National Health Scheme-To New Zealand belongs the credit---some say the discreditof establishing the first National Health Scheme. It is difficult yet to assess the effects of this experiment upon orthopaedic practice. At first, the knowledge that hospital accommodation was free caused serious overcrowding and at one time waiting lists for admission were quite ridiculously long. This situation is now being improved, but only through extensive building. One such new hospital at Middlemore near Auckland has been designed primarily as a special orthopaedic hospital. With large and airy six- and four-bedded wards, and with almost palatial accommodation for staff, it is a notable piece of hospital architecture.

The Health Scheme, with its remuneration arranged according to the number of patients seen each day, has been charged with responsibility for lowering the standard of specialist practice; but surely, if this were the case, fewer graduates would choose to spend several years seeking special training in England rather than taking up general practice with its promise of early financial reward.

The New Zealand Orthopaedic Association-Because of the sparsity of population, New Zealand cannot support a large number of cultural societies. Until recently, orthopaedic surgeons have had to depend upon local hospital clinical societies and upon the Royal Australasian College of Surgeons, whose members in New Zealand hold an annual general meeting at which orthopaedic papers are presented. This year the New Zealand Orthopaedic Association has been created under the patronage of Renfrew White and the presidency of Alexander Gillies. Its constitution resembles that of the British Orthopaedic Association. At the turn of the half-century the Association is still in the stage of creation. It values highly the recognition that has been afforded by the American and British Orthopaedic Associations and by the Journal of Bone and Joint Surgery, and it looks forward to the account that may be rendered at the turn of another half-century-A.D. 2000.

Special aspects of orthopaedic practice in New Zealand-Clinical material may not be abundant in New Zealand but certain orthopaedic conditions are more predominant than in Great Britain. Poliomyelitis is both endemic and epidemic. The epidemic disease is characterised by a high incidence of meningitic and encephalitic symptoms. During the recent epidemic, muscle spasm was found in almost every patient admitted to hospital. The 1948 epidemic produced some one thousand proven cases in a population of less than two millions and the proportion of undiagnosed morbidity to the number of proved cases was three hundred to one. Other unusual features of this epidemic were its persistence during the winter months, and the relatively high proportion of adults affected. The Department of Health and the profession as a whole took steps to control the epidemic by preventing public gatherings of children, prohibiting swimming in polluted waters, instructing the public to report minor morbidity to their doctors, and establishing a panel of consultants to screen suspects before admission to hospital. This last feature was most necessary in order to prevent catastrophic overcrowding of hospital accommodation.

Osteomyelitis-Another problem that seems to be peculiar to New Zealand is the unusually high incidence of acute haematogenous osteomyelitis with a seasonal incidence often associated with septicaemic manifestations. Taine (1947) reported thirty cases in the Auckland Hospital in one year, fourteen with staphylococcal septicaemia. The introduction of penicillin and other antibiotics has materially altered both the incidence and the prognosis of the "New Zealand disease." Nevertheless the annual report of the Crippled Children's Society this year shows that in 105 out of 1,581 children, the disability was from osteomyelitis.

Constitutional diseases such as rickets, scurvy and syphilis are seldom seen, and congenital anomalies other than club foot are infrequent. Tuberculosis of bones and joints is less common and, except in the Maori people, less formidable than in Britain.

Other contributions-Reference has already been made to the contributions of Harold Gillies, Archibald McIndoe and Rainsford Mowlem in the field of plastic and maxillo-facial surgery, and the transplantation of bone and cartilage. In 1936 James Jenkins of the Dunedin

Vol. $32 \mathrm{~B}$, No. 4, NOVEMBER 1950 
Hospital reported successful manipulative reduction of spondylolisthesis in a youth aged sixteen years and lumbo-sacral fusion by the transperitoneal route. In 1948 Batchelor of Guy's Hospital reported excision of the head and neck of the femur combined with subtrochanteric osteotomy of the Schantz type in selected cases of hip disorders, particularly ankylosing spondylitis, old fracture-dislocations of the hip and some cases of osteoarthritis and suppurative ankylosis of both hips; and he has also made contributions on the arthrography and treatment of congenital dislocation of the hip. From the Neurosurgical Unit in Dunedin Hospital, under Professor Falconer, there has originated a study of the diagnosis, radiography, surgery and results of treatment of lumbar intervertebral disc protrusions, published as a trilogy in the British Journal of Surgery. In $1948 \mathrm{~K}$. I. Nissen, now of London, drew attention to the work of Betts on plantar digital neuritis and attributed the nerve lesion to ischaemia from preceding degenerative changes in the corresponding artery. The tragic death of W. B. Highet during the recent war cut short the promise of a New Zealander who in Oxford had already contributed valuable studies; in 1941 he won the Jacksonian Prize for his essay "Injuries to Peripheral Nerves with Special Reference to the Late After-results "; and his contributions to the Lancet (1942) and the British Journal of Surgery (1943) showed the quality of work that would have been maintained if he had lived. Renfrew White's handbook Orthopaedic Physical Signs and Bandaging is familiar to students of the Otago Medical School. Morris Axford of Auckland discussed "Some Observations on the Cervical Sympathetic in Man" in 1928; Taine wrote an important article on "Penicillin in the Treatment of Acute Osteomyelitis " in 1947; and in the field of orthopaedic radiology, Richard Dawson has contributed a useful technique for recording accurately the length of limbs.

New Zealand is making a contribution to orthopaedic surgery not only in the developments that may be seen in this country but also through the work of her sons in other countries, particularly England.

Although this article appears over my name, my share has really been no more than to act as a type of sub-assistant-editor to senior colleagues: $\mathrm{Mr}$ Alexander Gillies of Wellington, $\mathrm{Dr} \mathrm{W}$. S. Wallis of Rotorua, and Mr Allan Macdonald, Mr Selwyn Morris and Mr Morris Axford of Auckland.

\section{REFERENCES}

Axford, Morris (1928): Some Observations on the Cervical Sympathetic in Man. Journal of Anatomy, 62, 301.

Batchelor, J. S. (1939): Discussion on Congenital Dislocation of the Hip. Proceedings of the Royal Society of Medicine (Section of Orthopaedics), 32, 1299.

Batchelor, J. S. (1948): Excision of the Femoral Head and Neck for Ankylosis and Arthritis of the Hip. Postgraduate Medical Journal, 24, 241.

Begg, A. C., Falconer, M. A., and McGeorge, M. (1946): Myelography in Lumbar Intervertebral Disc Lesions. British Journal of Surgery, 34, 141.

Dawson, R. (1948): Paper contributed to degree of M.Ch.Orth. (Liverpool).

Falconer, M. A., McGeorge, M., and BegG, A. C. (1948): Surgery of Lumbar Interbertebral Disc Protrusion. British Journal of Surgery, 35, 225.

Gillies, H. (1920): Plastic Surgery of the Face. London: Henry Frowde, Oxford University Press.

Highet, W. Bremner (1941): Jacksonian Prize Essay.

Highet, W. Bremner (1942): Splintage of Peripheral Nerve Injuries. Lancet, 1, 555.

Highet, W. Bremner, and Sanders, F. K. (1943): The Effects of Stretching Nerves after Suture. British Journal of Surgery, 30, 355.

Jenkins, J. A. (1936): Spondylolisthesis. British Journal of Surgery. 24, 80.

King, Truby (1938): Obituary. New Zealand Medical Journal, 37, 94.

Mowlem, Rainsford (1941): Bone and Cartilage Transplants. British Journal of Surgery, 29, 182.

Mowlem, Rainsford (1944): Cancellous Chip Bone-Grafts. Lancet, 2, 746.

Nissen, K. I. (1948): Plantar Digital Neuritis. Journal of Bone and Joint Surgery, 30-B, 213.

TAINe, G. J. (1947): Penicillin in the Treatment of Acute Haematogenous Osteomyelitis. New Zealand Medical Journal, 46, 178. 